RESEARCH ARTICLE

\title{
Antimicrobial Properties of the Probiotic Strain Bacillus Subtilis 534
}

\section{Olga Efremenkova ${ }^{1}$, Nina Gabrielyan ${ }^{2}$, Irina Malanicheva ${ }^{1}$, Mariya Demiankova ${ }^{1,2}$, Tatiana Efimenko1, Eugene Rogozhin $^{1,3}$, Sofiya Sharapchenko², Tatyana Krupenio ${ }^{2}$, Dmitrij Davydov $^{2}$ and Maksim Kornilov ${ }^{2}$}

${ }^{1}$ Gause Institute of New Antibiotics, Russia

${ }^{2}$ Academician V.I. Shumakov Federal Research Center of Transplantology and Artificial Organs, Russia

${ }^{3}$ Shemyakin and Ovchinnikov Institute of Bioorganic Chemistry Russian Academy of Sciences, Russia

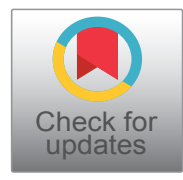

*Corresponding author: Olga Efremenkova, Sector of Search for Producers of Antibiotics that Overcome Bacterial Resistance, Gause Institute of New Antibiotics, Bolshaya Pirogovskaya 11, Moscow 119021, Russia, Tel: 8(499)-246-9980, Fax: 8(499)-245-0295

\begin{abstract}
Background: The effectiveness of antibiotic therapy is constantly decreasing due to the increasing spread of resistant pathogens. One alternative treatment for infections is the use of probiotics - living microorganisms that contribute to the normalization of the human microbiota. The aim of this study is to determine the antibiotic properties of the strain 534 as the intended basis of its probiotic activity.

Methods: The object of our research is the transient probiotic strain Bacillus subtilis 534 that is a basis of the drug Sporobacterin. The strain 534 was cultivated in submerged conditions and the obtained culture liquid $(C L)$ was investigated for antimicrobial activity by diffusion into the agar medium method. As test objects, collection strains of bacteria and fungi were used as well as clinical isolates with different resistance to antibiotics. For preliminary chemical characterization, CL was passed through a column with Amberlite XAD-2 sorbent. Antimicrobial components were desorbed with mix of n-butanol-acetone-water (1:1:1), resulting eluates were evaporated in vacuum to dryness and was dissolved in aqueous ethanol. The next purification of the antimicrobial components was performed in the column filled with Kieselgel 60 silica gel (Merck) using stepwise elution with chloroform-methanol solvents in different proportions. For determination of the active fractions, test strains of Staphylococcus aureus INA 00761 (methicillinresistant $S$. aureus - MRSA) and Saccharomyces cerevisiae RIA 259 were used.
\end{abstract}

Results: Under submerged cultivation, the strain 534 produces antimicrobial substances that suppress the growth of Gram-positive bacteria and fungi. The CL of the strain 534 inhibits the growth not only the test strains, but also clinical isolates with different antimicrobial resistance of the following Gram-positive bacteria and fungi: Staphylococcus aureus, S. epidermidis, S. capitis sbsp. urealyticus, Candidaalbicans, C. glabrata, C. Iusitaniae, Cryptococcus neoformans, Prototheca sp., Trichosporon sp. Although no activity against Gram-negative bacteria was detected in the $C L$, such activity was detected after CL concentration of approximately 800 times including activity against some clinical isolates of multidrug-resistant bacteria of the Klebsiella pneumonia and Acinetobacter baumannii species.

Conclusion: The spectrum of antimicrobial activity of $\mathrm{CL}$ indicates the ability of the probiotic strain $B$. subtilis 534 to produce antimicrobial substances active against wide range of bacteria and fungi, including those resistant to modern medical antibiotics. We consider this strain as a producer of antibiotics that overcome the drug resistance of pathogenic microorganisms and plan its further chemical research.

\section{Keywords}

Antibiotic resistance, Pathogenic microorganisms, Antimicrobial activity, Bacillus subtilis 534, Probiotic Sporobacterin

\section{Introduction}

The use of antibiotics in medicine began during the Second World War, but over the past decades, the effectiveness of antibiotic therapy is constantly decreasing due resistance development of pathogenic microorganisms [1-3]. The current situation requires the de-

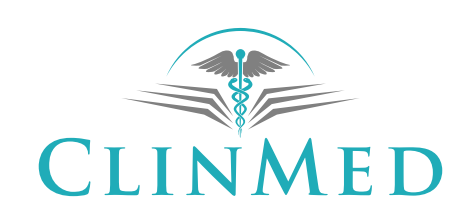

INTERNATIONAL LIBRARY 
velopment and introduction of new antibiotics into the medical practice, as well as other antimicrobial drugs. The latter include probiotics - drugs, which are based on living microorganisms that contribute to the normalization of the human microbiota. The term "probiotic" is also applied directly to probiotic microorganisms. The action of probiotics is multifactorial in nature, and one of the active principles is the formation of antibiotic substances that help restore the balance of microbiota. A valuable property of many probiotics is the lack of toxicity [4].

Probiotic microorganisms include such inhabitants of the intestine as streptococci, lactobacilli and bifidobacteria, as well as transient microorganisms, i.e. temporarily present in the human body. In particular, hay bacillus (Bacillus subtilis), which is widely distributed in nature and enters the human body with water and food, gives grounds for some researchers to consider this bacterium as a normal intestinal microbiota inhabitant [5-7]. The first bacillary probiotic described was the $B$. subtilis strain isolated from the wound in 1945 [8]. The result of subsequent research was the isolation from bacilli many antibiotics of different structure, active against both Gram-positive and Gram-negative microorganisms, as well as fungi [9-13]. In medical practice of different countries, biological preparations based on bacteria of the genus Bacillus are used. In Western Europe apply probiotic Baktisubtil (the company Marion Merrell, France) and its analogue Flonivin BS (the company Galenika, Slovenia). The basis of these preparations is $B$. cereus IP 5832 strain from the collection of the Institute Pasteur (France). Also known is the biological preparation Cereobiogen (Xing Jian, China), the active agent of which is $B$. cereus strain DM-423. The Vietnamese drug Biosubtil as an active ingredient contains the strain B. subtilis. Three bacilli-based drugs have been registered in Russia: Biosporin, Sporobacterin, Baktisporin. Biosporin is the only complex drug, which is based on two strains - B. subtilis 2335 and B. licheniformis 2336. Sporobacterin and Bactisporin are based on $B$. subtilis strains -534 and $3 \mathrm{H}$ respectively.

The drug Sporobacterin is a spore suspension of probiotic strain B. subtilis 534 in $7 \%$ aqueous sodium chloride solution. In Russia, probiotic Sporobacterin has been used for last thirty years, in particular, for the prevention and treatment of postoperative bacterial and fungal infections in high-tech surgery, including transplantation [14-16]. To date, the results of long-term clinical and laboratory studies have been published, according to which the use of Sporobacterin in the technology of early postoperative management of patients with cardio-surgical and transplant profiles opens up possibilities for optimizing the clinical condition of patients, and also significantly reduces the duration of antibiotic therapy courses [17-20]. The purpose of this study was to determine the ability of the strain 534 to produce antimicrobial substances under in vitro cultiva- tion conditions for the subsequent consideration of this strain as a medical antibiotics producer. Collection test strains and clinical isolates with different antibiotic resistance were used as test organisms.

\section{Materials and Methods}

\section{The object of the study}

Bacillus subtilis 534 is the basis of the probiotic Sporobacterin. The strain was deposited in the Microbiological Collection of the Gause Institute of New Antibiotics under the number INA 01122 (Russia). The sequence of the strain 534 is deposited in the GenBank database under the number KU051696 [21].

\section{Cultivation conditions}

Submerged cultivation of $B$. subtilis 534 strain was carried out using modified medium \#2 Gause of the following composition (\%): glucose - 1, peptone - 0.5, tryptone - $0.3, \mathrm{NaCl}-0.5$, tap water; $\mathrm{pH}$ 7.2-7.4. Spores of the strain 534 in an amount of $10^{6} / \mathrm{ml}$ were injected into $750 \mathrm{ml}$ Erlenmeyer flasks with $150 \mathrm{ml}$ of the medium, after which the flasks were placed on the rotary shaker with rotation speed $220 \mathrm{rpm}$ and incubated at $28^{\circ} \mathrm{C}$. Antimicrobial activity of the culture liquid $(\mathrm{CL})$ was determined at 2, 4 and 7 days of cultivation. Twelve cultivations were carried out with at least three parallel trials.

For surface cultivation of all test microorganisms universal for bacteria and fungi agar variant of the modified medium \#2 Gause was used with the addition of 2\% agar. Fungal strains Aspergillus niger INA 00760, Saccharomyces cerevisiae RIA 259 and bacterial strains Comamonas terrigena VKPM B-7571 and Leuconostoc mesenteroides VKPM B-4177 were grown at $28{ }^{\circ} \mathrm{C}$, all other strains, including clinical isolates and the probiotic strain B. subtilis 534 , at $37^{\circ} \mathrm{C}$. The duration of all test strains cultivation was $20 \mathrm{~h}$.

\section{Isolation and purification of antimicrobial compo- nents}

Through the column filled with $80 \mathrm{ml}$ of Amberlite XAD-2 sorbent, 0.8 I of culture liquid of Bacillus subtilis 534 strain was passed. Antimicrobial components were desorbed with "n-butanol-acetone-water" (1:1:1) at neutral $\mathrm{pH}$. The resulting eluates were evaporated in vacuum to dryness at $37{ }^{\circ} \mathrm{C}$ and the dry residue was dissolved in $60 \%$ aqueous ethanol. Further purification of the antimicrobial components was performed in the column filled with Kieselgel 60 silica gel (Merck) using stepwise elution with chloroform-methanol solvents $(9: 1,8: 2,7: 3,6: 4$ and 5:5). The fractions from the column were tested for biological activity against test strains of Staphylococcus aureus INA 00761 (MRSA) and Sac. cerevisiae RIA 259. The active fractions was evaporated to dryness, dissolved in $1 \mathrm{ml}$ of methanol each (800-fold concentration) and analyzed by thin layer chromatography (TLC) on silica gel plates in a 
Table 1: Antimicrobial spectrum against collection strains and the highest established level of antimicrobial activity in Bacillus subtilis 534 cultural liquid (CL).

\begin{tabular}{|l|l|}
\hline Test-strains & $\begin{array}{l}\text { Growth } \\
\text { inhibition } \\
\text { zones of CL, } \\
\text { mm }\end{array}$ \\
\hline Bacillus mycoides 537 & $16-18$ \\
\hline Bacillus pumilus NCTC 8241 & $22-24$ \\
\hline Bacillus subtilis ATCC 6633 & $10-12$ \\
\hline Leuconostoc mesenteroides VKPM B-4177 & $16-18$ \\
\hline Micrococcus luteus NCTC 8340 & $23-25$ \\
\hline Staphylococcus aureus FDA 209P (MSSA) & $22-30$ \\
\hline Staphylococcus aureus INA 00761 (MRSA) & $25-27$ \\
\hline Staphylococcus epidermidis INA 01121* & $22-23$ \\
\hline Comamonas terrigena VKPM B-7571 & 0 \\
\hline Escherichia coli ATCC 25922 & 0 \\
\hline Pseudomonas aeruginosa ATCC 27853 & 0 \\
\hline Aspergillus niger INA 00760 & $18-22$ \\
\hline Saccharomyces cerevisiae RIA 259 & $19-25$ \\
\hline & \\
\hline
\end{tabular}

solvent system ethyl acetate-methanol (1:4) followed by bioautography. Of the three selected active components antimicrobial properties the component \#1 with $R_{f}=0.7$ was studied in more details.

\section{Test organisms and determination of antimicrobial activity}

As tests for determining antimicrobial activity, we used international collection strains of Gram-positive and Gram-negative bacteria, fungi (Table 1), as well as clinical isolates of pathogenic microorganisms with different antibiotic resistance (Table 2, Table 3, Table 4 and Table 5). The species identification of clinical isolates of pathogenic microorganisms, as well as their susceptibility/resistance to antibiotics was carried out on an automated bacteriological analyzer for the identification of microorganisms Siemens MicroScan Walk Away - 96 Plus System. The antimicrobial activity of the culture liquid $(\mathrm{CL})$ of $B$. subtilis 534 and its active component extracted was determined by agar-diffusion method. By $100 \mu \mathrm{l}$ of $\mathrm{CL}$ were introduced into the wells with a diameter of $9 \mathrm{~mm}$ in the agar medium contaminated with the test organism. The

${ }^{*}$ Clinical isolates.

Table 2: Antimicrobial activity of the Bacillus subtilis 534 cultural liquid (CL) against clinical isolates of Staphylococcus spp.

\begin{tabular}{|c|c|c|c|c|c|}
\hline \multirow[t]{2}{*}{ Species, clinical isolates } & \multirow{2}{*}{$\begin{array}{l}\text { Growth } \\
\text { inhibition zones } \\
\text { of } \mathrm{CL}, \mathrm{mm}\end{array}$} & \multicolumn{4}{|c|}{$\begin{array}{l}\text { The susceptibility/resistance of clinical isolates against } 22 \text { medical } \\
\text { antibiotics }^{*}\end{array}$} \\
\hline & & $\mathbf{R}$ & $\mathbf{I}$ & $\mathbf{S}$ & Details:** \\
\hline S. aureus 2476 & 0 & 3 & 0 & 18 & 3R: P, AM, LVX \\
\hline S. capitis sbsp. urealyticus 1133 & 17 & 2 & 0 & 20 & 2R: P, AM \\
\hline S. epidermidis 2480 & 0 & 16 & 0 & 6 & 6S: DAP, E, RA, SYN, TE, VA \\
\hline S. epidermidis 2432 & 0 & 16 & 0 & 6 & 6S: DAP, E, RA, SYN, TE, VA \\
\hline S. epidermidis 2624 & 25 & 15 & 0 & 5 & 5S: DAP, LZD, RA, SYN, VA \\
\hline S. epidermidis 2688 & 0 & 16 & 0 & 4 & 4S: DAP, RA, TE, VA \\
\hline S. epidermidis 1217 & $(17)^{\star \star \star *}$ & 11 & 1 & 10 & $\begin{array}{l}\text { 10S: C, CC, DAP, LZD, OX, RA, SYN, TE, SXT, VA } \\
\text { 1I: MXF }\end{array}$ \\
\hline S. epidermidis 1259 & 0 & 12 & 0 & 10 & $\begin{array}{l}\text { 10S: C, CC, DAP, LZD, MXF, RA, SYN, TE, SXT, } \\
\text { VA }\end{array}$ \\
\hline S. epidermidis 1306 & 0 & 6 & 0 & 16 & 6R: AM, E, LVX, P, TE, SXT \\
\hline S. epidermidis 1319 & 0 & 3 & 1 & 18 & $\begin{array}{l}\text { 3R: AM, E, P } \\
\text { 1I: C }\end{array}$ \\
\hline S. epidermidis 1401 & 0 & 14 & 1 & 7 & $\begin{array}{l}\text { 7S: C, CC, DAP, LZD, RA, SYN, VA } \\
\text { 1I: MXF }\end{array}$ \\
\hline S. epidermidis 1109 & 0 & 11 & 0 & 10 & $\begin{array}{l}\text { 10S: C, CC, DAP, LZD, MXF, RA, SYN, TE, SXT, } \\
\text { VA }\end{array}$ \\
\hline S. haemolyticus 4126 & 0 & 17 & 0 & 5 & 5S: DAP, RA, SYN, SXT, VA \\
\hline $\begin{array}{l}\text { S. hominis } \\
\text { sbsp. Novobiosepticus } 4221\end{array}$ & 0 & 14 & 0 & 8 & 8S: SAM, DAP, MXF, OX, RA, SYN, SXT, VA \\
\hline S. xylosus 1298 & 0 & 15 & 0 & 6 & 6S: C, GM, LVX, MXF, TE, SXT \\
\hline
\end{tabular}

*Antibiotics: AM: Ampicillin; AN: Amikacin; ATM: Aztreonam; C: Chloramphenicol; CC: Clindamycin; DAP: Daptomycin; E: Erythromycin; GM: Gentamicin; IPM: Imipenem; LZD: Linezolid; LVX: Levofloxacin; MEM: Meropenem; MXF: Moxifloxacin; NN: Tobramycin; OX: Oxacillin; P: Penicillin; RA: Rifampin; SAM: Ampicillin/Sulbactam; SXT: Trimethoprim/Sulfamethoxazole; SYN: Synercid; TE: Tetracyclin; VA: Vancomycin.

"R: Resistance; I: Intermediate susceptibility; S: Susceptibility.

${ }^{* *}$ Growth oppression. 
Table 3: The activity of the component \#1 of the $B$. subtilis 534 antibacterial complex against clinical isolates of $A$. baumannii.

\begin{tabular}{|c|c|c|c|c|}
\hline \multirow[t]{2}{*}{$\begin{array}{l}\text { Clinical isolates, } \\
\text { \#\# }\end{array}$} & \multirow[t]{2}{*}{$\begin{array}{l}\text { Growth inhibition zones of } \\
\text { component \#1, } \mathrm{mm}\end{array}$} & \multicolumn{3}{|c|}{$\begin{array}{l}\text { The susceptibility/resistance of clinical isolates against } 15 \\
\text { medical antibiotics* }\end{array}$} \\
\hline & & $\mathbf{R}$ & I & $\mathbf{S}$ \\
\hline 1630 & 9 & 15 & 0 & 0 \\
\hline 1839 & 9 & 14 & 1 (SAM) & 0 \\
\hline 2050 & 9 & 15 & 0 & 0 \\
\hline 2455 & 8 & 15 & 0 & 0 \\
\hline 2617 & 12 & 15 & 0 & 0 \\
\hline 3037 & 10 & 14 & $1(\mathrm{GM})$ & 0 \\
\hline 3050 & 0 & 13 & 2(GM, PIP) & 0 \\
\hline 3122 & 7 & 15 & 0 & 0 \\
\hline 3164 & 0 & 13 & $2(\mathrm{GM}, \mathrm{LVX})$ & 0 \\
\hline 0 & 7 & 15 & & 0 \\
\hline 0 & 8 & 15 & & 0 \\
\hline 3238 & 7 & 12 & 3(GM, FEP, SAM) & 0 \\
\hline 3255 & Trace ${ }^{* * *}$ & 15 & 0 & 0 \\
\hline 3275 & Trace $^{\star \star *}$ & 3 & 5(PIP, GM, CRO) & $\begin{array}{l}\text { 7(AN, FEP, SAM, } \\
\text { CIP, LVX, MEM, NN) }\end{array}$ \\
\hline 3613 & Trace $^{\star \star \star}$ & 15 & 0 & 0 \\
\hline 4006 & Trace $^{* * *}$ & 15 & 0 & 0 \\
\hline 4066 & Trace $^{* \star *}$ & 15 & 0 & 0 \\
\hline 4074 & Trace $^{* \star *}$ & 15 & 0 & 0 \\
\hline 4165 & 9 & 13 & 1(MEM) & $1(\mathrm{TE})$ \\
\hline 4200 & Trace $^{* * *}$ & 15 & 0 & 0 \\
\hline 4315 & Trace ${ }^{* * *}$ & 15 & 0 & 0 \\
\hline 4354 & 8 & 15 & 0 & 0 \\
\hline 4372 & 0 & 15 & 0 & 0 \\
\hline 4374 & 0 & 13 & 1(MEM) & $1(\mathrm{TE})$ \\
\hline
\end{tabular}

"Antibiotics: AN: Amikacin; SAM: Ampicillin/Sulbactam; GM: Gentamicin; IPM: Imipenem; LVX: Levofloxacin; MEM: Meropenem; PIP: Piperacillin; TE: Tetracycline; NN: Tobramycin; SXT: Trimethoprim/Sulfamethoxazole; FEP: Cefepime; CTX: Cefotaxime; CAZ: Ceftazidime; CRO: Ceftriaxone; CIP: Ciprofloxacin; R: Resistance; I: Intermediate susceptibility; S: Susceptibility.

***"Trace" - The thickness of the ring of the growth inhibition zone around the hole in agar medium with the sample which is tested for antimicrobial activity does not exceed $1 \mathrm{~mm}$.

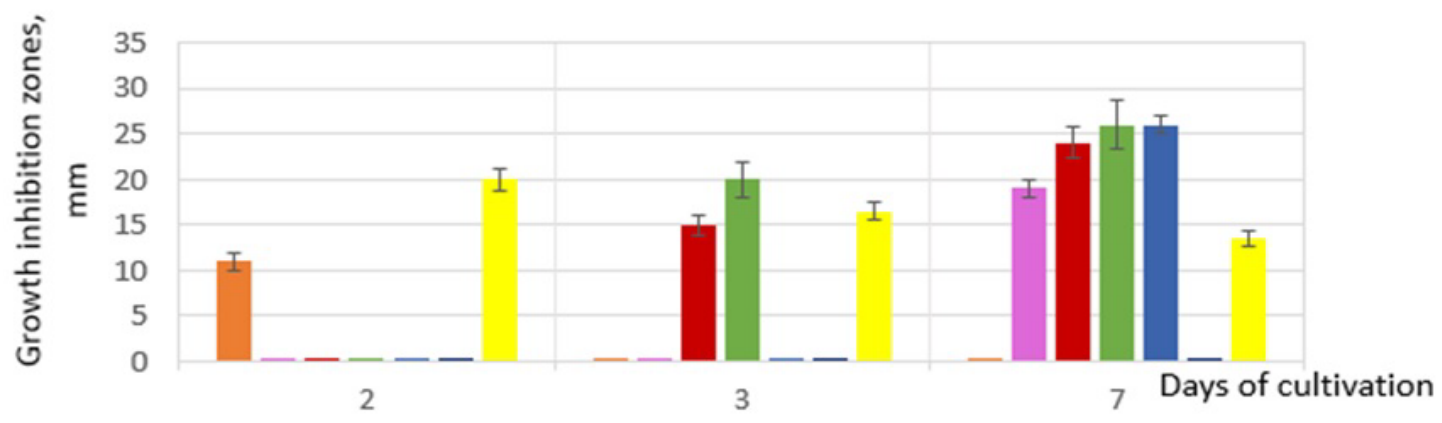

Bacillus subtilis ATCC 6633

- Micrococcus luteus NCTC 8340

- Staphylococcus aureus INA 00761 (MRSA)

Saccharomyces cerevisiae RIA 259
- Bacillus pumilus NCTC 8241

- Staphylococcus aureus FDA 209P (MSSA)

- Escherichia coli ATCC 25922

Figure 1: Dynamics of the strain B. subtilis 534 antimicrobial activity during submerged cultivation. 
selected antimicrobial component was applied to the disks with a diameter of $6 \mathrm{~mm}$ and placed on the surface of the agar medium.

\section{Results}

It was shown that the strain 534 produces and isolates to $\mathrm{CL}$ antimicrobial components with different antimicrobial spectrum, the maximum activity of which are achieved in different time (Figure 1). From Figure 1 it follows that in the $\mathrm{CL}$ there are at least four different compounds or groups of compounds that differ in antimicrobial activity:

- Antibacterial activity only in respect of $B$. subtilis

Table 4: Antimicrobial activity of the component \#1 of the $B$. subtilis 534 antibacterial complex against clinical isolates of $K$. pneumoniae.

\begin{tabular}{|c|c|c|c|c|c|c|}
\hline \multirow[t]{2}{*}{$\begin{array}{l}\text { Clinical } \\
\text { isolates, \#\# }\end{array}$} & \multicolumn{2}{|c|}{$\begin{array}{l}\text { Growth inhibition zones, } \\
\mathrm{mm}\end{array}$} & \multicolumn{4}{|c|}{$\begin{array}{l}\text { The susceptibility/resistance of clinical isolates against 24-28 medical } \\
\text { antibiotics }^{*}\end{array}$} \\
\hline & CL & Component \#1 & $\mathbf{R}$ & I & $\mathbf{S}$ & Details: ${ }^{* *}$ \\
\hline 320 & 0 & 0 & 19 & 1 & 6 & $\begin{array}{l}\text { 6S: FOX, IPM, MEM, TGC, PMB, CL } \\
\text { 1I: TE }\end{array}$ \\
\hline 634 & 0 & 0 & 17 & 1 & 8 & $\begin{array}{l}\text { 8S: AN, FOX, IPM, MEM, LVX, TGC, PMB, CL } \\
\text { 1I: CIP }\end{array}$ \\
\hline 692 & 0 & 0 & 20 & 1 & 7 & $\begin{array}{l}\text { 7S: AN, FOX, ETP, IPM, MEM, PMB, CL } \\
\text { 1I: TGC }\end{array}$ \\
\hline 775 & 0 & 0 & 16 & 1 & 9 & $\begin{array}{l}\text { 9S: AN, GM, IPM, MEM, TE, TGC, SXT, PMB, CL } \\
\text { 1I: FOX }\end{array}$ \\
\hline 821 & 0 & 11 & 23 & 0 & 3 & 3S: TGC, PMB, CL \\
\hline 1050 & 0 & 0 & 17 & 2 & 5 & $\begin{array}{l}\text { 5S: AN, GM, IPM, PMB, CL } \\
\text { 2I: TGC, NN }\end{array}$ \\
\hline 1054 & 0 & $(11)^{* *}$ & 19 & 1 & 4 & $\begin{array}{l}\text { 4S: FOX, IPM, MEM, TGC } \\
\text { 1I: LVX }\end{array}$ \\
\hline 1071 & 0 & $(9)^{* *}$ & 20 & 0 & 4 & 4S: ATM, FEP, CAZ, CRO \\
\hline 1074 & 0 & $(11)^{* *}$ & 23 & 3 & 0 & 3I: PIP/TAZ, PMB, CL \\
\hline 1114 & Trace $^{\star \star \star}$ & 7 & 20 & 2 & 4 & $\begin{array}{l}\text { 4S: AN, GM, PMB, CL } \\
\text { 2I: TGC, NN }\end{array}$ \\
\hline 1878 & 0 & 8 & 23 & 1 & 0 & 1I: TGC \\
\hline 2080 & Trace $^{* * *}$ & Trace $^{* * *}$ & 23 & 1 & 0 & 1I: TGC \\
\hline 2266 & 0 & 0 & 23 & 0 & 3 & 3S: CAZ, TGC, PMB \\
\hline 2427 & 0 & 0 & 23 & 0 & 2 & 2S: TGC, PMB \\
\hline 2663 & 0 & 0 & 23 & 0 & 2 & 2S: TGC, PMB \\
\hline 3168 & - & $(9)^{* *}$ & 22 & 1 & 3 & $\begin{array}{l}\text { 3S: TGC, PMB, CL } \\
\text { 1I: TE }\end{array}$ \\
\hline 3186 & - & 0 & 23 & 0 & 3 & 3S: TGC, PMB, CL \\
\hline 3266 & - & 0 & 22 & 0 & 4 & 4S: CIP, LVX, PMB, CL \\
\hline 4095 & - & $(8)^{* *}$ & 23 & 1 & 2 & $\begin{array}{l}\text { 2S: PMB, CL } \\
\text { 1I: } T G C\end{array}$ \\
\hline 4261 & - & 0 & 19 & 0 & 7 & 7S: ATM, FEP, CAZ, CIP, LVX, PMB, CL \\
\hline 4353 & - & 0 & 14 & 1 & 11 & $\begin{array}{l}\text { 11S: ATM, FEP, CTX, CAZ, CRO, IPM, MEM, CIP, } \\
\text { LVX, PMB, CL } \\
\text { 1I: TGC }\end{array}$ \\
\hline 4375 & 0 & 0 & 17 & 0 & 8 & 8S: AN, ETP, GM, IPM, MEM, TGC, PMB, CL \\
\hline
\end{tabular}

"Antibiotics: AN: Amikacin; ATM: Aztreonam; C: Chloramphenicol; CAZ: Ceftazidime; CIP: Ciprofloxacin; CL: Colistin; CRO: Ceftriaxone; CTX: Cefotaxime; E: Erythromycin; ETP: Ertapenem; FEP: Cefepime; FOX: Cefoxitin; GM: Gentamicin; IPM: Imipenem; LVX: Levofloxacin; MEM: Meropenem; MXF: Moxifloxacin; NN: Tobramycin; OX: Oxacillin; P: Penicillin; PIP: Piperacillin; PIP/TAZ: Piperacillin/Tazobactam; PMB: Polymyxin B; RA: Rifampin; SXT: Trimethoprim/Sulfamethoxazole; TE: Tetracycline; TGC: Tigecycline; R: Resistance; I: Intermediate susceptibility; S: Susceptibility.

*- Growth oppression.

***"Trace" - The thickness of the ring of the growth inhibition zone around the hole in agar medium with the sample which is tested for antimicrobial activity does not exceed $1 \mathrm{~mm}$. 
Table 5: Growth inhibition zones of the clinical isolates of pathogenic fungi under the action of the culture liquid (CL) of the strain B. subtilis 534 (diameters in $\mathrm{mm}$ ).

\begin{tabular}{|c|c|c|c|c|c|c|c|}
\hline \multirow[t]{3}{*}{ Species, strains } & \multirow{3}{*}{$\begin{array}{l}\text { Growth } \\
\text { inhibition } \\
\text { zones of } \mathrm{CL} \text {, } \\
\mathrm{mm}\end{array}$} & \multicolumn{6}{|c|}{ Medical antimycotics } \\
\hline & & \multirow{2}{*}{\begin{tabular}{|l} 
Pyrimidine \\
5 FC \\
\end{tabular}} & \multirow{2}{*}{$\begin{array}{l}\text { Polyene } \\
\text { AB }\end{array}$} & \multicolumn{2}{|c|}{ Imidazoles } & \multicolumn{2}{|c|}{ Triazoles } \\
\hline & & & & MCZ & KET & ITR & FLU \\
\hline Candida albicans 58 & 18 & S & $\mathrm{R}$ & $\mathrm{R}$ & $\mathrm{R}$ & $\mathrm{R}$ & $\mathrm{R}$ \\
\hline C. albicans 182 & 19 & S & S & S & $\mathrm{S}$ & $\mathrm{s}$ & S \\
\hline C. albicans 265 & 29 & $S$ & $\mathrm{R}$ & $S$ & $\mathrm{~S}$ & 1 & S \\
\hline C. albicans 317 & 20 & $S$ & $\mathrm{~s}$ & $\mathrm{R}$ & $\mathrm{R}$ & $\mathrm{R}$ & $\mathrm{R}$ \\
\hline C. albicans 456 & 23 & $S$ & $\mathrm{R}$ & 1 & 1 & 1 & S \\
\hline C. albicans 458 & 17 & $S$ & $\mathrm{R}$ & $R$ & $\mathrm{R}$ & $\mathrm{R}$ & $\mathrm{R}$ \\
\hline C. albicans 848 & 28 & S & $\mathrm{R}$ & $\mathrm{R}$ & $\mathrm{R}$ & $\mathrm{R}$ & $\mathrm{R}$ \\
\hline C. albicans 922 & 24 & $S$ & I & $\mathrm{R}$ & $\mathrm{R}$ & $\mathrm{R}$ & $\mathrm{R}$ \\
\hline C. albicans 1187 & 19 & S & 1 & 1 & S & I & S \\
\hline C. albicans 1294 & 31 & $S$ & $\mathrm{R}$ & $R$ & $\mathrm{R}$ & $\mathrm{R}$ & $\mathrm{R}$ \\
\hline C. albicans 1610 & 0 & $\mathrm{~s}$ & S & $\mathrm{R}$ & 1 & $S$ & S \\
\hline C. albicans 1815 & 36 & S & $\mathrm{R}$ & 1 & $\mathrm{~S}$ & 1 & S \\
\hline C. albicans 2122 & 0 & S & $S$ & 1 & 1 & I & I \\
\hline C. albicans 2356 & 12 & $\mathrm{R}$ & $\mathrm{R}$ & $\mathrm{R}$ & $\mathrm{R}$ & $\mathrm{R}$ & $\mathrm{R}$ \\
\hline C. albicans 4166 & 25 & $\mathrm{R}$ & I & $\mathrm{R}$ & $\mathrm{R}$ & I & $\mathrm{R}$ \\
\hline C. albicans 4244 & 25 & $R$ & $\mathrm{R}$ & $R$ & $\mathrm{R}$ & 1 & $\mathrm{R}$ \\
\hline C. albicans 4438 & 24 & $\mathrm{R}$ & $S$ & I & S & 1 & $\mathrm{R}$ \\
\hline C. albicans 4895 & 24 & $S$ & $\mathrm{R}$ & 1 & $\mathrm{R}$ & $\mathrm{R}$ & $\mathrm{R}$ \\
\hline C. albicans 4897 & 24 & S & $S$ & S & 1 & $\mathrm{R}$ & $\mathrm{R}$ \\
\hline C. albicans 5228 & 14 & $R$ & $\mathrm{R}$ & 1 & $\mathrm{R}$ & $R$ & $\mathrm{R}$ \\
\hline C. albicans 5721 & 24 & S & $\mathrm{R}$ & 1 & $\mathrm{R}$ & $R$ & $\mathrm{R}$ \\
\hline C. albicans 5963 & 18 & 1 & $\mathrm{R}$ & $\mathrm{R}$ & $\mathrm{R}$ & $\mathrm{R}$ & $\mathrm{R}$ \\
\hline C. albicans 6107 & 17 & $R$ & $\mathrm{R}$ & $R$ & I & $R$ & S \\
\hline C. catenulata 1507 & 0 & $R$ & 1 & I & 1 & 1 & $\mathrm{R}$ \\
\hline C. catenulata 6093 & 0 & $S$ & $\mathrm{R}$ & 1 & I & $R$ & I \\
\hline C. glabrata 13 & 0 & S & $\mathrm{R}$ & I & I & I & I \\
\hline C. glabrata 212 & 18 & $S$ & $R$ & $R$ & $R$ & $R$ & $R$ \\
\hline C. krusei 247 & 0 & S & $S$ & $\mathrm{R}$ & s & 1 & S \\
\hline C. Iusitaniae 5254 & 22 & $S$ & $\mathrm{R}$ & 1 & $S$ & 1 & $S$ \\
\hline C. parapsilosis 1380 & 0 & $\mathrm{R}$ & $S$ & $S$ & S & 1 & S \\
\hline C. tropicalis 455 & 0 & $S$ & $\mathrm{R}$ & $R$ & $\mathrm{R}$ & $R$ & $\mathrm{R}$ \\
\hline Cryptococcus neoformans 25 & 0 & S & $\mathrm{R}$ & 1 & I & $\mathrm{R}$ & I \\
\hline C. neoformans 245 & 25 & $\mathrm{R}$ & $\mathrm{R}$ & $S$ & I & I & I \\
\hline Prototheca sp. $110^{* *}$ & 27 & S & $\mathrm{R}$ & $R$ & $\mathrm{R}$ & $\mathrm{R}$ & $\mathrm{R}$ \\
\hline Prototheca sp. 1376 & 0 & $\mathrm{R}$ & $S$ & $S$ & $\mathrm{~S}$ & I & $S$ \\
\hline Prototheca sp. 6017 & 0 & S & $\mathrm{R}$ & 1 & $\mathrm{R}$ & $\mathrm{R}$ & I \\
\hline Prototheca sp. 6047 & 24 & $S$ & $\mathrm{R}$ & $\mathrm{R}$ & $\mathrm{R}$ & $\mathrm{R}$ & $\mathrm{R}$ \\
\hline Trichosporon sp. БM1.5 & 24 & I & S & I & I & I & S \\
\hline
\end{tabular}

*Antimycotics: 5 FC: 5-flucytosine; AB: AmphotericinB; MCZ: Miconazole; KET: Ketoconazole; ITR: Itraconazole; FLU: Fluconazole; R: Resistance; I: Intermediate susceptibility; S: Susceptibility.

**- representatives of the genus Prototheca are chlorophyll-free algae; antimycotics are used to treat Prototheca infections.

ATCC 6633 strain and only on the second day of cultivation; such activity may be due to bacteriocin;

- Antifungal activity, the peak of which falls on the second day and gradually decreases by the seventh day;

- Antibacterial activity against M. luteus NCTC 8340 and S. aureus FDA 209P (methicillin-sensitive S. aureus -MSSA), which is manifested on the third day 


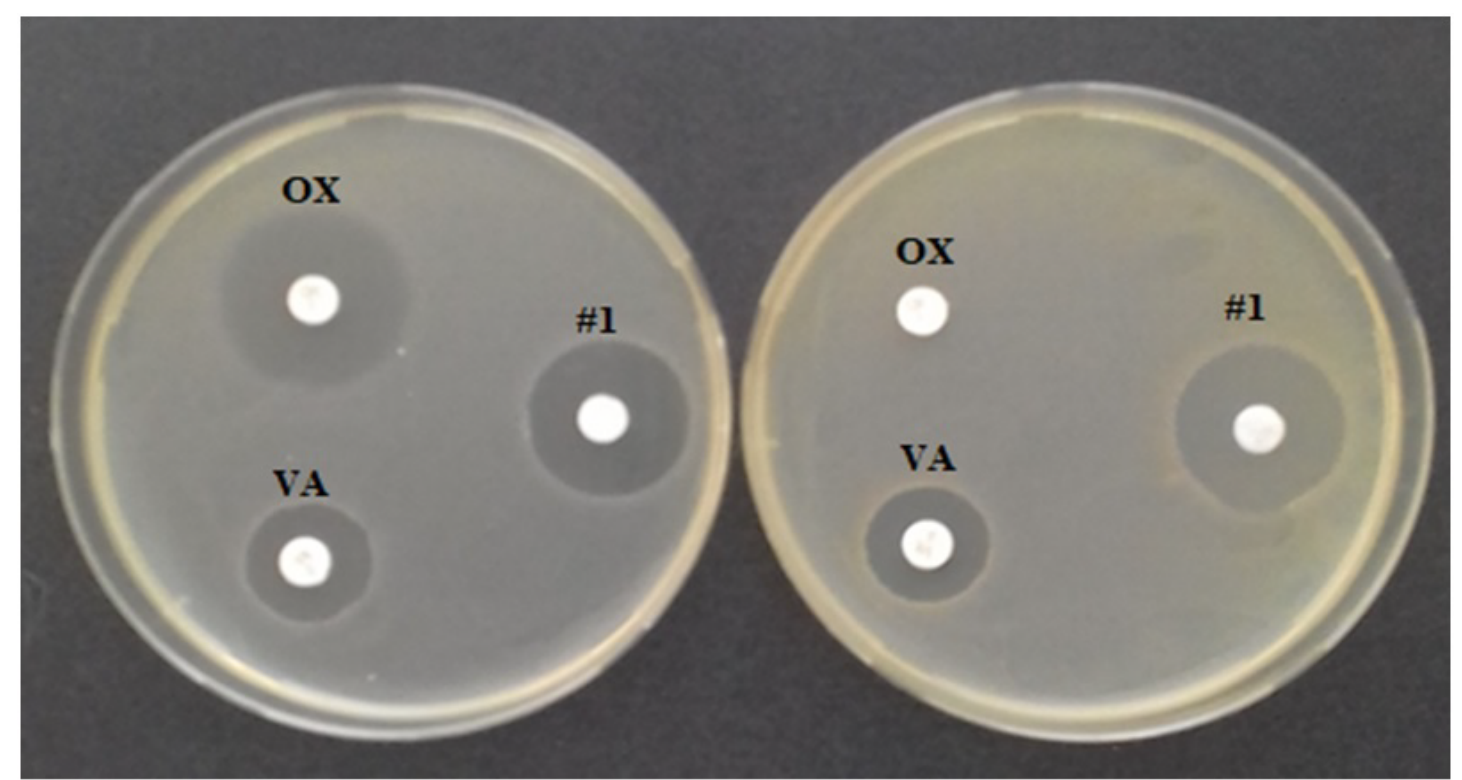

Figure 2: Antibiotic sensitivity of two S. aureus strains: FDA 209P (MSSA, left) and INA 00761 (MRSA, right). On the left side of the cups there are disks with $1 \mathrm{mcg}$ of oxacillin (OX, above) and $5 \mathrm{mcg}$ of vancomycin (VA, below). On the right sides is a disc with $5 \mathrm{mcl}$ of the component \#1 from CL of the strain 534 .

of cultivation and increases on the seventh day;

- Antibacterial activity against B. pumilus NCTC 8241 and S. aureus INA 00761 (MRSA).

The maximum possible levels of antimicrobial activity in the above-described culture conditions are given in Table 1. From Figure 1 and Table 1 it follows that strain 534 inhibits the growth of Gram-positive bacteria and fungi. It is important to note that $\mathrm{CL}$ is active against resistant to methicillin and oxacillin Staphylococcus aureus (MRSA) and the Leuconostoc mesenteroides VKPM B-4177 test strain with a high level of natural resistance to vancomycin.

At the next stage, the antimicrobial activity of the culture liquid of strain 534 against 15 clinical isolates of the genus Staphylococcus was tested (Table 2). For two clinical isolates of $S$. capitis sbsp. urealyticus 1133 and S. epidermidis 2624 it was showed pronounced antimicrobial activity. It is important to note that strain 2624 is resistant to 15 medical antibiotics out of 20 , so as effective drugs may be used only 5 antibiotics: daptomycin, linezolid, rifampin, synercid and vancomycin. Subsequently, in a chemical study of the culture liquid of strain 534, microbiological control with the release of the active components was carried out using the MRSA test strain INA 00761 (Figure 2).

The culture liquid of $B$. subtilis 534 showed no activity against collection strains of Gram-negative bacteria (Table 1). However, when isolating and, accordingly, increasing the concentration of component $\# 1$, which according to preliminary estimates consisted of polypeptide compounds, such activity was observed against a number of clinical isolates of Gram-negative bacteria (Table 3 and Table 4). Although the level of activity of component \#1 in relation to $A$. baumannii and $K$. pneumoniae clinical isolates is low, further biotechnological and chemical research is reasonable, since multidrug-resistant bacteria are susceptible to component \#1.For example, A. baumannii clinical isolates $1630,2050,2455,2617,3122,3166,3208$, and 4354 as well as K. pneumonia 1878 are sensitive to component \#1, but resistant to all tested modern medical antibiotics. Analysis of component \#1 showed that it consists of no less than twenty substances, of which five are quantitatively predominant. Three of the five components confirmed antibiotic activity. According to preliminary data, it can be assumed that the active substances are of peptide nature.

\section{Discussion}

The drug Sporobacterin is a suspension of $B$. subtilis 534 spores in $7 \%$ aqueous solution of sodium chloride that is intended for oral administration. We have previously shown that Sporobacterin itself does not possess antibiotic properties in vitro [21]. On the contrary, in the conditions of submersed cultivation of the strain 534 in a nutrient medium, a broad spectrum of antimicrobial activity is manifested. On the other hand, it is known that the stay of $B$. subtilis in the intestines of warm-blooded animals lasts from 10 to 30 days, and the bacteria are present both in the form of vegetative cells and spores. The process of germination and sporulation of spores is repeated several times before excretion from the body with feces $[22,23]$.

Based on this data, we assumed that in the intestine and in the nutrient medium in flasks developmental processes of $B$. subtilis are similar and bacterial biosynthesis of antimicrobial substances in the digestive tract is possible. The ability of strain 534 to secrete antibacterial and antifungal substances may be the main explanation 
for the effectiveness of Sporobacterin in preventing the development and in treatment of bacterial and fungal infections along with such properties as enhancing immunity, stimulating the growth of normal intestinal microflora and secretion of digestive enzymes. It is especially valuable that the probiotic strain 534 is capable to produce substances that overcome the antibiotic resistance of clinical isolates of a number of Gram-positive bacteria and fungi. As for Gram-negative bacteria, it is also possible the manifestation of antimicrobial activity in vitro, albeit to with low intensity. Since B. subtilis 534 is capable to produce substances active against clinical isolates with a different spectrum of resistance to modern antibiotics, it can be assumed that these substances have different molecular targets in cells (or on the surface of cells) of pathogenic microorganisms. We are currently considering the $B$. subtilis 534 strain as a producer of antibiotics and are working on identifying the produced antimicrobial compounds.

Is it possible to detect new antibiotics in $B$. subtilis? Among the bacilli, the $B$. subtilis species takes the first place in the number of described antibiotics of various chemical nature, among which are polyketide antibiotics [24], phospholipids [25], polyenes [25-28], macrolactins [29] and various peptides that differ by chemical nature, by the mechanism of biosynthesis and by antimicrobial spectra. Some $B$. subtilis antibiotics are used as modern medicines. The peptide antibiotic bacitracin, one of the first antibiotics described in 1945 and formed by the $B$. subtilis strain isolated from a human wound, is still used in medicine [8]. A number of close antibiotics forming the bacitracin complex are currently known [30]. Due to the low toxicity in 2010, bacitracin was approved in the United States for the treatment of staphylococcal infections in newborns [9]. The combination of bacitracin with neomycin is effective against most clinical isolates of resistant staphylococcus (MRSA) that is very important for modern antimicrobial therapy [31]. Among the $B$. subtilis peptides, relatively large peptide antibiotics are bacteriocins, having a molecular weight of tens of thousands of Daltons, characterized by a narrow spectrum of antibiotic activity and acting on other strains of B. subtilis, i.e. acting as an intraspecific regulatory factor $[8,32,33]$. Among bacteriocins, antibiotics with a relatively small molecular weight of 5-10 kilo Dalton, which are called microcins, are isolated into an independent group [30]. Among the peptide antibiotics of $B$. subtilis, there is also a group of lantibiotics compounds, which include the rare thioether amino acid lanthionine and its derivatives, due to which internal thioester bonds are formed in the antibiotic molecule. Lantibiotics of $B$. subtilis, for example, subtilin and ericin, unlike bacteriocins, have a broad antimicrobial spectrum of action. Subtilin, consisting of 32 amino acids and having a pentacyclic structure, is similar in structure to the preservative nisin, widely used in the food industry and formed by Lactococcus lactis [9]. From fermented soybeans, tradition- al Korean food, B. subtilis strain the antibiotic SC- 8 was isolated, which exhibits a narrow spectrum of antimicrobial activity against bacteria of the Bacillus cereus group and contributes to food preservation [31]. In B. subtilis also was described a large group of broad-spectrum lipopeptide antibiotics. These are oligopeptides synthesized on multienzyme complexes, to which fatty acids are then added. The amino acid chain and fatty acid bacillar lipopeptides are divided into three families. Representatives of the iturin family are heptapeptides with a lipophilic $\beta$-amino acid. They have a pronounced efficacy against mycelial and yeast phytopathogenic fungi $[34,35]$. Decapeptides with lipophilic $\beta$-hydroxy acid belong to the fenicine family and are characterized by the presence of ornithine. They are characterized by efficiency against filamentous fungi $[36,37]$. The third family includes surfactins - heptapeptides with $\beta$-hydroxy fatty acid, which are less effective against fungi, but exhibiting the most pronounced hydrophobic properties among these lipopeptides, which allow the formation of stable biofilms on the surface of plants and prevent their colonization by other microorganisms. In this case, $B$. subtilis antibiotics play an important role in ecosystems, contributing to the formation of biofilms and the colonization of area [32,38,39]. The oligopeptides of the lowest molecular weight, containing only two or three amino acids, include rhizocticins, which were isolated as antifungal phosphono-oligopeptides from the $\mathrm{CL}$ of collection strain $B$. subtilis ATCC 6633 . These peptides contain a non-protein amino acid (Z)-2-amino-5-phosphono-3-pentenoic acid [34].

Since $B$. subtilis is a cosmopolitan species and is found on a wide variety of substrates, it is characterized by wide adaptability to various environmental conditions, which, in particular, is reflected in the wide variety of antibiotics produced, and we should expect further description of new antibiotics $B$. subtilis.

\section{Conclusions}

Strain B. subtilis 534 refers to probiotics and has long been successfully used in medicine, being the basis of the drug Sporobacterin. The use of Sporobacterin is not toxic and not burdensome to patients, but can be effective. Since it was established that strain 534 exhibits antimicrobial activity under conditions of submerged cultivation, we consider it as a potential producer of antimicrobial substances that overcome the multidrug resistance of pathogenic microorganisms. It is advisable to continue further chemical research and clinical trials of antimicrobial substances with the prospect of their use as medical antibiotics.

\section{Acknowledgments}

The authors thank all the reviewers for improving the quality of the manuscript. Also we want to thank Svetlana Dolgorukova for technical assistance. 


\section{Conflicts of Interest}

All authors declare no conflicts of interest.

\section{Sources of Support}

The research was carried out within the framework of the state assignment at the Gause Institute of New Antibiotics. The study was supported in part by the Russian Foundation for Basic Research, a grant of 17-00$00393 \backslash 18$.

\section{References}

1. Butler MS, Blaskovich MA, Cooper (2013) MA Antibiotics in the clinical pipeline in 2013. J Antibiot (Tokyo) 66: 571-591.

2. Butler MS, Blaskovich MA, Cooper MA (2017) Antibiotics in the clinical pipeline at the end of 2015. J Antibiot (Tokyo) 70: 3-24.

3. O'Neill J (2016) The Review on Antimicrobial Resistance. Tackling Drug-Resistant Infections Globally: Final Report and Recommendations.

4. Duc LH, Hong HA, Barbosa TM, Henriques AO, Cutting SM (2004) Characterization of bacillus probiotics available for human use. Appl Environ Microbiol 70: 2161-2171.

5. Pokhilenko VD, Perelygin VV (2007) Probiotics on the basis of spore-forming bacteria and their safety. Chemical and Biological Safety 2-3: 20-41.

6. Skrypnik IN, Maslova AS (2009) Modern spore-forming probiotics in clinical practice. Modern Gastroenterology (Ukrain) 3: 81-90.

7. Savustianenko AV (2016) Mechanisms of action of probiotics based on Bacillus subtilis. Actual Infectology 2: 35-44.

8. Johnson B, Anker H, Meleney F (1945) Bacitracin: A new antibiotic produced by a member of the $B$ subtilis group. Science 102: 376-377.

9. Fickers $P$ (2012) Antibiotic compounds from Bacillus: Why are they so amazing? Am J Biochem and Biotech 8: 40-46.

10. Stein T (2005) Bacillus subtilis antibiotics: Structures, syntheses and specific functions. Molecular Microbiol 56: 845-857.

11. Baruzzi F, Quintieri L, Morea M, Caputo L (2011) Antimicrobial compounds produced by bacillus spp. and applications in food. In: Vilas AM (ed.). Science against microbial pathogens: Communicating current research and technological advances. Formatex, Badajoz, Spain, 1102-1111.

12. Cotter PD, Ross RP, Hill C (2013) Bacteriocins - A viable alternative to antibiotics? Nat Rev Microbiol 11: 95-105.

13. Sumi CD, Yang BW, Yeo IC, Hahm YT (2015) Antimicrobial peptides of the genus Bacillus: A new era for antibiotics. Can J Microbiol 61: 93-103.

14. Nikitenko VI, Polyakova BC, Nikitenko MV (2001) The drug Sporobacterin. New data on the mechanism of action of this and other living bacterial preparations. Scientific Bulletin of the Tyumen Medical Academy 2: 70-72.

15. Nikitenko VI, Nikitenko IK (1988) The bacterial strain Bacillus subtilis used to obtain the drug for the prevention and treatment of inflammatory processes and allergic diseases. Patent SU 1723116 A1. USSR.

16. Nikitenko MV, Nikitenko VI (2001) Drug sporobacterin liquid. Patent RU2217154C2.
17. Gabrielyan NI, Suskova VS, Suskov SI, Vologodskaya NL (2012) Study of the effect of probiotic Sporobacterin on the functional state of granulocyte-macrophage cells of blood donors in vitro. Bulletin of Experimental Biology and Medicine. 153: 653-655.

18. Kazakov EN, Gabrielyan NI, Senchenko OR, Petrakov KV, Arefieva LI, et al. (2013) To the question of the prevention of infectious complications after cardiac surgery in cardiopulmonary bypass. Russian Medical Journal 2: 1316.

19. Arefieva LI, Gorskaya EM, Savostiyanova OA, Senchenko OR, Gabrielyan NI (2013) Infectious complications of a bacterial nature in cardiovascular surgery. Russian Medical Journal 3: 36-42.

20. Gabrielyan NI, Arefieva LI, Gorskaya EM, Kornilov MN, Moysyuk YG, et al. (2013) The use of biological products in abdominal surgery and liver transplantation. Russian Journal of Transplantology and Artificial Organs 2: 48-155.

21. Gabrielyan NI, Gorskaya EM, Krupenio TV, Zenkova VA, Efimenko TA, et al. (2016) Evaluation of the antimicrobial activity of bacillary probiotic Bacillus subtilis (strain 534). Epidemiology and infectious diseases. Current Issues 1: 41-47.

22. Osipova IG, Sorokulova IB, Vasilieva EA, Budanova EV (2005) Preclinical testing of new spore probiotics. Vestn Ross Akad Med Nauk 12: 36-40.

23. Leser TD, Knarreborg A, Worm J (2008) Germination and outgrowth of Bacillus subtilis and Bacillus licheniformis spores in the gastrointestinal tract of pigs. J Appl Microbiol 104: 1025-1033.

24. Bostian M, McNitt K, Aszalos A, Berdy J (1977) Antibiotic identification: A computerized data base system. J Antibiot 30: 633-634.

25. Egorov ES, Baranova IN (1999) Bacteriocins: Formation, properties, and application. Antibiot Khimioter 6: 33-40.

26. Rea MC, Ross RP, Cotter PD, Hill C (2011) Classification of bacteriocins from Gram-positive bacteria. In: Drider D, Rebuffat S, Prokaryotic Antimicrobial Peptides: From Genes to Applications. Springer, New York, 29-53.

27. Abriouel H, Franz CMAP, Ben Omar N, Galvez A (2011) Diversity and applications of Bacillus bacteriocins. FEMS Microbiol Rev 35: 201-232.

28. SeverinovK, Semenova E, Kazakov T (2011) Class I microcins: Their structures, activities, and mechanisms of resistance. In: Drider D, Rebuffat S, Prokaryotic Antimicrobial Peptides: From Genes to Applications. Springer, New York, 289-308.

29. Ross RP, Morgan S, Hill C (2002) Preservation and fermentation: Past, present and future. Int J Food Microbiol 79: 3-16.

30. Ikai Y, Oka H, Hayakawa J, Harada K-I, Suzuki M (1992) Structural characterization of bacitracin components by fritfast atom bombardment (FAB) liquid chromatography/mass spectrometry (LC/MS). J Antibiot 45: 1325-1334.

31. Suzuki M, Yamada K, Nagao M, Aoki E, Matsumoto M, et al. (2011) Antimicrobial ointments and methicillin-resistant Staphylococcus aureus USA300. Emerg Infect Dis 17: 1917-1920.

32. Raaijmakers JM, De Bruijn I, Nybroe O, Ongena M (2010) Natural functions of lipopeptides from Bacillus and Pseudomonas: More than surfactants and antibiotics. FEMS Microbiol Rev 34: 1037-1062.

33. Fredenhagen A, Angst C, Peter HH (1995) Digestion of 
rhizocticins to (Z)-L-2-amino-5-phosphono-3-pentenoic acid: Revision of the absolute configuration of plumbemycins A and B. J Antibiot 48: 1043-1045.

34. Thimon L, Peypoux F, Wallach J, Michel G (1995) Effect of the lipopeptide antibiotic, iturin $A$, on morphology and membrane ultrastruture of yeast cell. FEMS Microbiol Lett 128: 101-106.

35. Tsuge K, Akiyama T, Shoda M (2001) Cloning, sequencing, and characterization of the iturin A operon. J Bacteriol 183: 6265-6273.

36. Steller S, Vollenbroich D, Leenders F, Stein T, Conrad B, et al. (1999) Structural and functional organization of the fengycin synthetase multienzyme system from Bacillus subtilis b213 and A1/3. Chem Biol 6: 31-41.

37. Vanittanakom N, Loeffer W, Koch U, Jung G (1986) Fengycin - A novel antifungal lipopeptide antibiotic produced by Bacillus subtilis F-29-3. J Antibiot (Tokyo) 39: 888-901.

38. Magnet-Dana R, Thimon L, Peypoux F, Ptak M (1992) Surfactin/iturin $A$ interactions may explain the synergistic effect of surfactin on the biological properties of iturin $A$. Biochimie 74: 1047-1051.

39. Bais H P, Fall R, Vivanco J M (2004) Biocontrol of Bacillus subtilis against infection of Arabidopsis roots by Pseudomonas syringae is facilitated by biofilm formation and surfactin production. Plant Physiol 134: 307-319. 